\title{
KOROVKIN TYPE APPROXIMATION THEOREMS IN WEIGHTED SPACES VIA POWER SERIES METHOD
}

\author{
E. TAŞ, T. YurdakAdim And O. G. ATLIHAN
}

Abstract. In this paper we consider power series method which is also member of the class of all continuous summability methods. We study a Korovkin type approximation theorem for a sequence of positive linear operators acting from a weighted space $C_{\rho_{1}}$ into a weighted space $B_{\rho_{2}}$ with the use of the power series method which includes both Abel and Borel methods. We also consider the rates of convergence of these operators.

Mathematics subject classification (2010): Primary 41A36, 41A25, Secondary 40C15.

Keywords and phrases: Power series method, Korovkin type theorem, weighted space, rates of convergence.

\section{REFERENCES}

[1] F. Altomare and M. Campiti, Korovkin type Approximation Theory and its Applications, Walter de Gruyter Publ. Berlin, 1994.

[2] O. G. Atlihan And C. ORhan, Matrix summability and positive linear operators, Positivity 11 (2007), 387-398.

[3] H. Berens AND R. A. Devore, Quantitative Korovkin theorems for $L_{p}$-spaces, in: Approximation Theory II, in: Proc.Internat. Sympos., Unýv. Texas, Austin, Tex, Academic Press, New York, 1976, pp. 289-298.

[4] R. BoJANiC AND M. K. KHAn, Summability of Hermite-Fejer interpolation for functions of bounded variation, J. Natur. Sci. Math. 32 (1992), 5-10.

[5] J. Boos, Classical and Modern Methods in Summability, Oxford Science Publ., New York, 2000.

[6] O. Duman, M. K. KhAn And C. ORHAN, A-statistical convergence of approximating operators, Math. Inequal. Appl. 6 (2003), 689-699.

[7] A. D. GADJIEv AND C. ORHAN, Some approximation theorems via statistical convergence, Rocky Mountain J. Math. 32 (2002), 129-138.

[8] S. Goldberg AND A. MeIr, Minimum moduli of ordinary differential operators, Proc. Lond. Math. Soc. 23 (1971), 1-15.

[9] A. Holhoş, Quantitative estimates for positive linear operators in weighted spaces, Gen. Math. 16 (2008), 99-110.

[10] J. P. King And J. J. Swetits, Positive linear operators and summability, J. Aust. Math. Soc. 11 (1970), 281-290.

[11] P. P. Korovkin, Linear Operators and Approximation Theory, Hindustan Publ. Co., Delhi, 1960.

[12] I. SAKAOGlu And C. ORHAN, Strong summation process in $L_{p}$ spaces, Nonlinear Analysis 86 (2013), 89-94.

[13] J. J. Swetits, On summability and positive linear operators, J. Approx. Theory 25 (1979), 186-188.

[14] J. J. SWeTITS AND B. WoOd, Quantitative estimates for $L_{p}$ approximation with positive linear operators, J. Approx. Theory 38 (1983), 81-89.

[15] J. J. SWetiTS AND B. Wood, On the degree of $L_{p}$ approximation with positive linear operators, J. Approx. Theory 87 (1996), 239-241.

[16] M. Unver, Abel transforms of positive linear operators on weigthed spaces, Bull. Belg. Math. Soc. Simon Stevin 21 (2014), 813-822. 